\title{
How would serpentinization on Mars have been different than on Earth?
}

\author{
BENJAMIN TUTOLO ${ }^{1}$ AND NICHOLAS J. TOSCA ${ }^{2}$
}

${ }^{1}$ University of Calgary, Department of Geoscience

${ }^{2}$ University of Cambridge

Presenting Author: benjamin.tutolo@ucalgary.ca

Serpentinization has garnered attention in the quest to constrain the origins of life on Earth and the search for habitable worlds beyond. Nevertheless, "serpentinization" is a general term given to the group of reactions associated with the hydration of ultramafic rocks, and, while immense insight into the general nature of serpentinization has been gained by studying terrestrial serpentinizing systems, serpentinization reactions, and the fluids and minerals that they generate, are incredibly diverse. It is unlikely that serpentinization on Mars, for example, would have behaved similarly to the classic examples of serpentinization with which many geochemists are familiar. Most importantly, insitu and orbital data indicate important compositional differences between protoliths hosting serpentinization reactions on early Mars and terrestrial mantle peridotite, which consists largely of magnesian ( $\sim 90 \% \mathrm{Mg}$ end-members) olivine and pyroxene. First, Martian protoliths, such as olivine-rich gabbro or troctolite, contain significant proportions of plagioclase in addition to olivine and minor pyroxene. In addition, olivine tends to be significantly more Fe-rich than terrestrial mantle olivines. Thus, the closest terrestrial analogues to Martian serpentinizing systems represent atypical systems, such as those associated with the hydrothermal alteration of (ultra)mafic igneous intrusions. To this end, we have studied serpentinization of the Duluth Complex (USA) rocks with primary and alteration mineralogy strikingly similar to that identified in both orbiter and rover mineralogical analyses. Using a combination of chemical and redox analyses of the Duluth Complex samples, we demonstrate a unique progression of alteration reactions in Mars-analogue serpentinites. Importantly, the $\mathrm{Fe}$ in the serpentinized rocks of the Duluth Complex is typically highly oxidized, which is generally consistent with typical seafloor serpentinites, but the mode of $\mathrm{Fe}^{3+}$ substitution trends towards hisingerite rather than cronstedtite; this observation carries important consequences for $\mathrm{H}_{2}(a q)$ production. Moreover, these rocks show evidence of $\mathrm{Mg}$ mobility, which would require acidic fluids instead of the highly alkaline fluids associated with many serpentinites. This new understanding of Duluth Complex serpentinization suggests that both the chemistry of serpentinizing fluids on Mars and $\mathrm{H}_{2}(a q)$ production would have been subject to thermodynamic and kinetic controls quite different from more intensively studied styles of serpentinization on Earth. 